\title{
Using principles of landscape design in farm planting
}

\author{
MARION B. MACKAY \\ Institute of Natural Resources, Massey University \\ m.b.mackay@massey.ac.nz
}

\begin{abstract}
Farm planting can be improved visually by using principles of landscape design to organise both site layout and planting. Principles of site layout include unity, patterning, and manipulation of mass and space, views, focal points and circulation. Planting design should make best use of the visual characters of plants namely line, form, colour and texture. Individual areas of planting are organised using principles of planting composition, while over the whole site principles of balance and sequential development are used. Planting should make best use of interesting plant species and seasonal effects.
\end{abstract}

\section{Introduction}

Landscape design is concerned with the functional, spatial and visual layout of a site so that the site is functionally efficient but also develops maximum aesthetic effect. Design principles can be applied at any scale and to a wide variety of sites, so how can the key elements of landscape design be applied to farm plantings? First, by developing a coherent spatial and visual organisation so that the site looks interesting and provides a stimulating 'journey' as we move through it. Here we manipulate pattern, mass and space, enclosure and openness, views and viewing lines, focal points and finally circulation - these ideas are outlined in the following section. Second, by organising planting so that areas of green mass complement and enhance the spatial organisation. Here we manipulate combinations of visual characters of plants (line, form, colour, texture) to create scenes that have the right balance of theme and contrast, and then arrange those scenes over the whole property in a sequential organisation - these ideas are outlined in the section of principles of plant composition.

\section{Principles of site layout}

For most people landscape design is perceived at a subconscious level - we know we like a particular site, but may not be able to identify why it is 'right'. The theory of landscape preference shows that certain factors trigger a 'liking' response in most viewers (Ulrich 1983) and not surprisingly these factors are closely related to the principles of landscape design (Hannebaum 1994). Several of those preference triggers relate to the need for coherent organisation in a site; in design terms this is some kind of repeated idea or theme that holds a design together and which establishes unity. In most designs techniques such as pattern, proportion, materials, and planting are used to generate unity. Another 
group of preference triggers relate to spatial organisation that provides an interesting 'journey' as the viewer progresses around the site. Design techniques here include manipulation of spatial character and enclosure, circulation, views and viewing points, and focal points.

\section{Unity through pattern, planting and materials}

Unity is a key design outcome. Unity is achieved when the viewer feels (usually subconsciously) that a design 'holds together' - a feeling that everything makes a coherent whole. This response is related to the preference factors of complexity and structure, i.e. the number of elements in a scene, their organisation and the relationship between them. Getting these organisational matters 'right' is the whole point of a design plan, and there are several useful approaches.

Unity is usually achieved through ground pattern, with a repeated idea appearing in each space. In this plan (Figure 1) a circle (or parts of it) and a rectangle are repeated to generate the ground layout. Often the underlying device is simple (e.g. a rectangle of certain proportions), but these usually make good designs as they are easy for the viewer to 'read'.

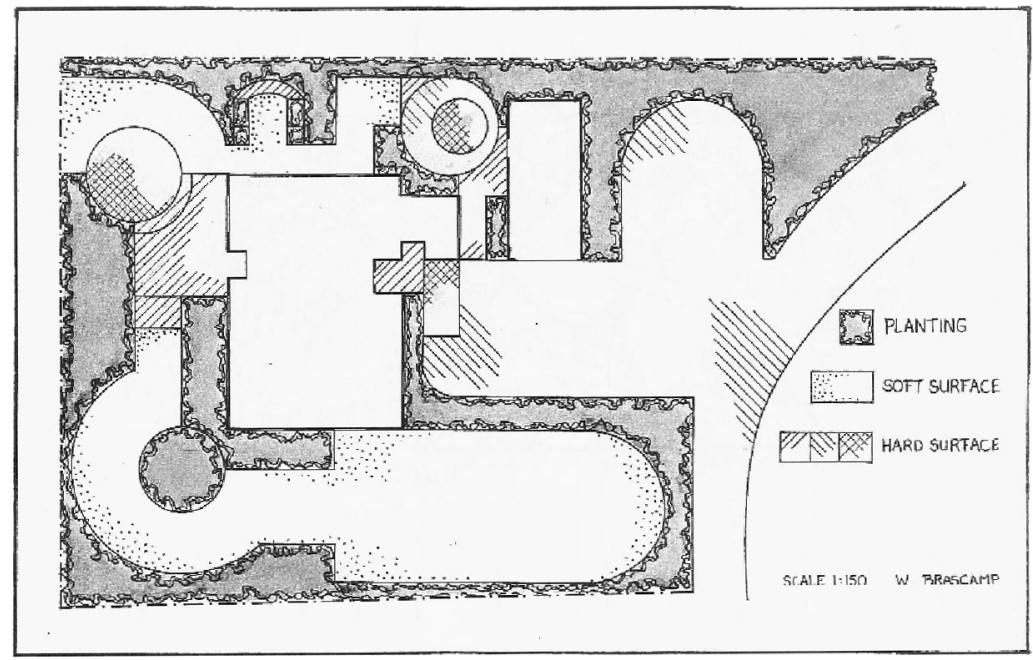

Figure 1. Coherent organisation of a site is generated with a repeated pattern idea. (Drawing by W.Brascamp, page 10, study guide 1 for 171.360 Landscape Design Practice, Massey University)

While geometry is an obvious form of ground patterning for urban areas and around houses, freeform approaches are also used, particularly in large gardens 
and on rural sites. Figure 2 shows a largely freeform layout for a small park area; note the consistency of shape and size of spaces even though the spaces are not geometric. In this respect repetition of a certain proportion within the pattern is most important - proportion is read subconsciously by most viewers, nevertheless it is a powerful connecting factor when used well. Poorly established proportion makes most viewers feel uncomfortable even though they might not be able to identify a specific problem.

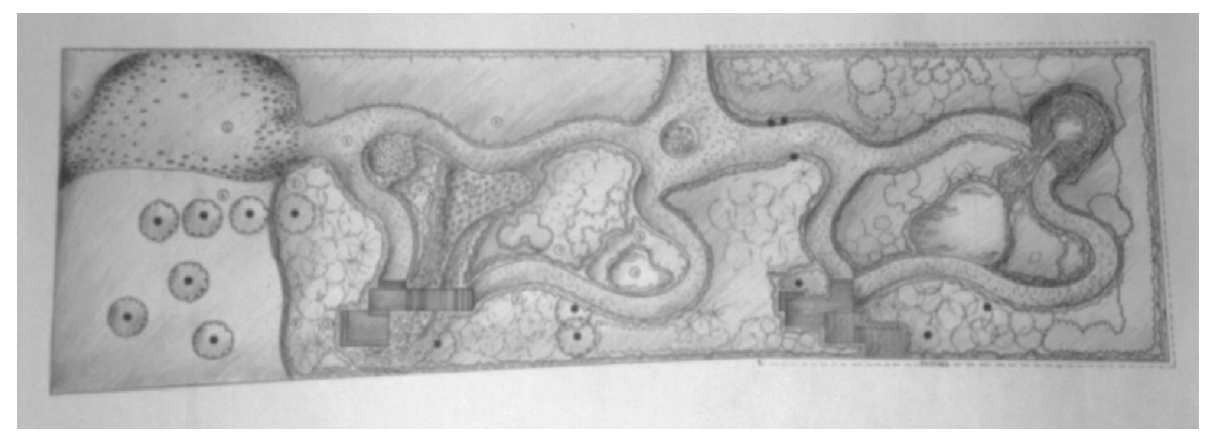

Figure 2. An example of freeform pattern for the Karaka Grove. Design by Martha Dravitzki, landscape design student 2002, Massey University. (The slight distortion in the plan is the fault of the photographer, the original plan is rectangular).

Which pattern type to use, in which circumstance, and of which form, is a skill designers spend considerable time learning. Pattern forms may be suggested by landform or existing vegetation and structures. Patterns are often in sympathy with the surrounding landscape but in some cases we develop deliberate contrast. Good use of pattern and proportion triggers the preference factor of complexity (Ulrich, 1983), where most viewers prefer landscapes that are neither too simple nor too busy and occupy a satisfying middle range.

In addition to ground pattern, unity is also supported with repeated materials and styles of built elements. Unity may also be conveyed through a repeated planting colour, species, or placements. In the best designs all of the aforementioned methods work together to create that feeling that the whole site belongs together. How do we do this on the farm? Repeated colour and form in planting are an obvious choice, supported by repeated planting placements, e.g. repeated avenues or ridge top plantings. Repeated materials and styles in buildings and other structures can also be used. Ground pattern is less likely as the shapes and sizes of areas are driven by your farming operations, but you may be able to take advantage of the coincidental patterns of shape and size that your paddocks make. 


\section{Spatial manipulations}

As we develop the pattern of the design we also manipulate several factors that influence the 'journey' that the viewer experiences as they move through the landscape. Progression through a series of spaces of different shapes and sizes, with varying enclosure and views, makes for an interesting and stimulating passage through the site. There are two key factors: what kinds of spaces there are and how we move through them. In design terms these are spatial and circulatory manipulation and they are controlled by a series of interacting factors, namely enclosure, views and focal points (Motloch 1991; Simonds 1983).

Variable use of enclosure creates spaces of different sizes, and influences both views and circulation. The importance of enclosure in determining spatial character is illustrated below (Figure 3) where the forward placement of enclosure in the right hand scene completely alters the depth and view of the same area of ground.
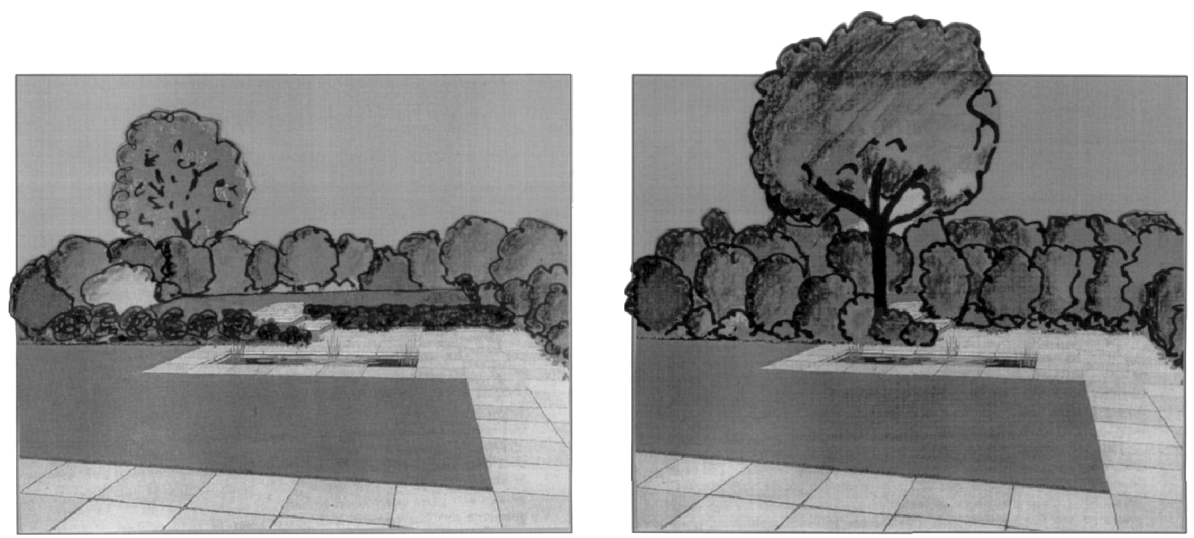

Figure 3. The effect of differing enclosure on spatial character (adapted from page 31 of Farthing, D. and G. Farthing. 1991. Practical garden design. W. Foulsham and Co. Ltd, Slough.)

Enclosure is usually associated with the vertical plane and the position, height and extent of enclosure can be manipulated, e.g. in Figure 3 the left hand scene allows a view to the end of the space, while the right hand scene does not.

Enclosure interacts with shape - enclosure of long narrow spaces creates a strongly directional space that encourages movement (in people anyway!) and therefore has a circulatory effect (Figure 4). (Add a focal element at the end of the axis and the effect is even stronger). Size and degree of enclosure also interact with topography - a small clearing in a valley has a different effect to the same space on a high point. The height of enclosure also interacts with the scale of the space - very tall enclosure of a small space overwhelms. 
Partial enclosure, where something is partly hidden around the corner, has a strong circulatory effect as the promise of more information stimulates most people to find out what is hidden. (e.g. what will we find if we cross the bridge in Figure 7).

Spatial character is also influenced by the ground plane - in park or garden design patterns are made on the ground with paving and planting, while on farms this technique could be applied with plantings in the grass that are safe for stock. When combined, manipulations of shape, size and enclosure of space, along with topography, provide many opportunities for the designer to create interest on a site.

An obvious flow-on from the manipulation of space and enclosure is the development of views and viewing points. Careful control

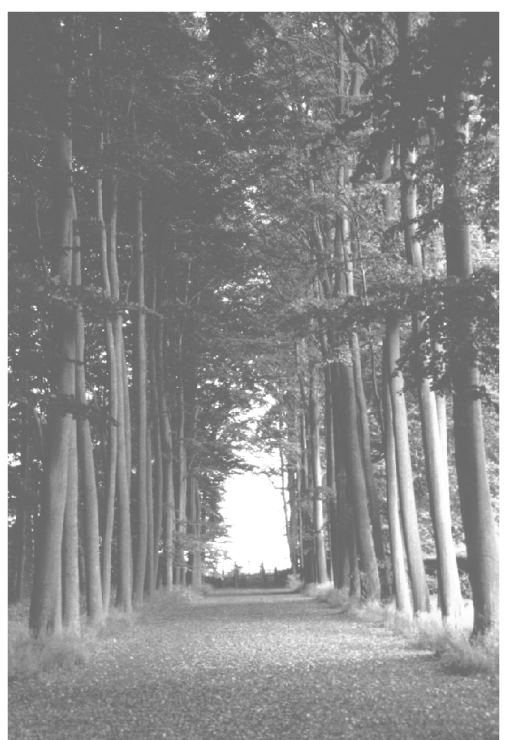

Figure 4. Enclosure of a narrow space stimulates movement. of which views are allowed, and from where they should be seen, is part of the interest of the journey. Enclosure is critical in view development and we manipulate the height, position and extent of openings (Figure 5). Using enclosure to allow glimpses of the view until the true viewing station is reached is another way of creating interest.

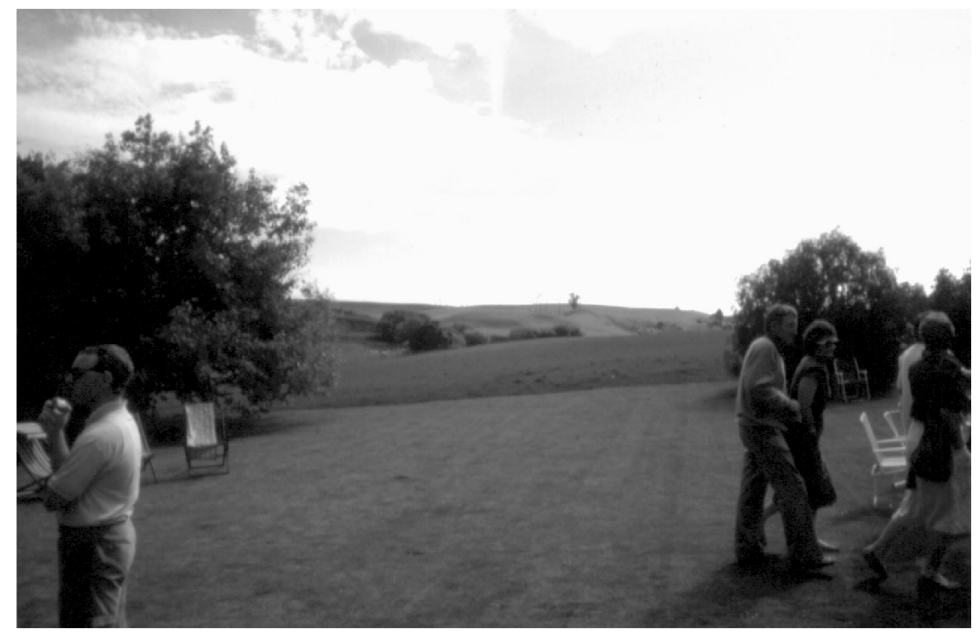

Figure 5. Partial enclosure of this space allows a view of the farm. 
Depending on the nature of your property, views may be narrow or extensive, on a long or short axis, and internal or external (don't forget to borrow from the neighbours!). Given your farming operations, manipulation of enclosure may be limited, but you could take advantage of topography again. Hills and valleys could be used to screen and reveal, with interesting views being discovered as one moves from one landform to the next. Using planting to support view development is an added bonus.

Related to the issue of views is the question of focal points. These are deliberately sited elements to draw attention to a particular part of the landscape. Focal points are often views, but are also created using strongly contrasting plants or objects (Figures 6,7).

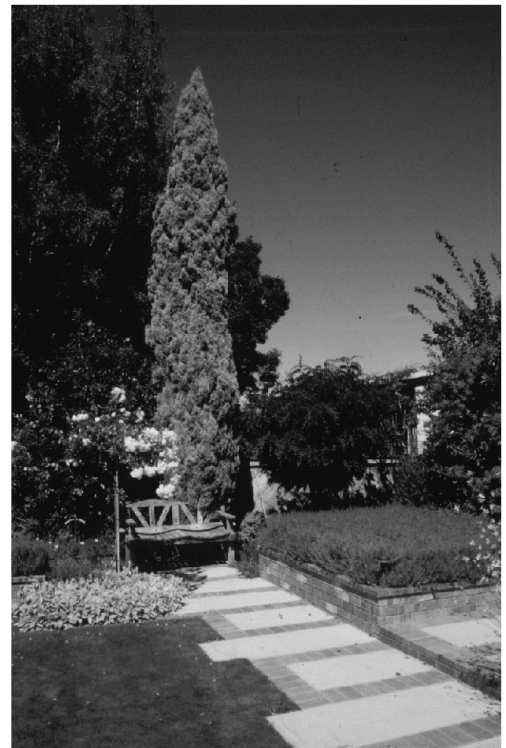

Figure 6. A plant of strong colour or form can be used as a focal point.

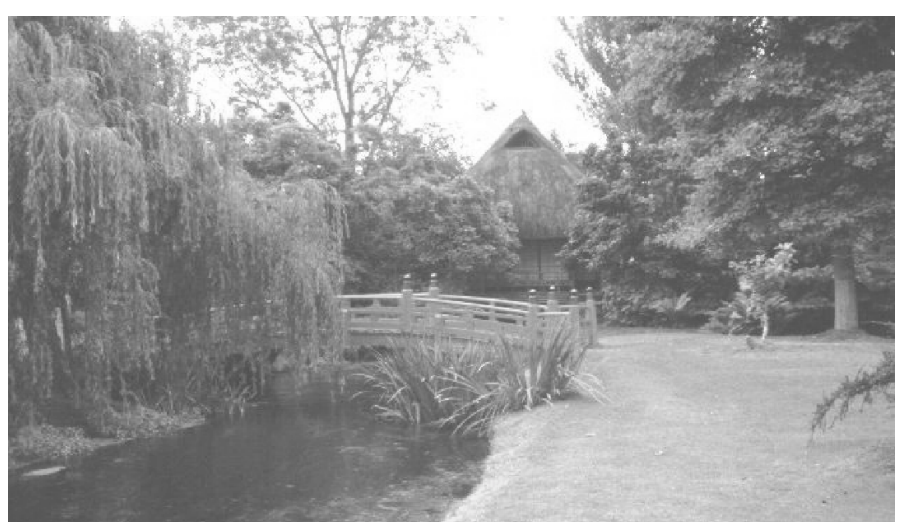

Figure 7. An object can be used as a focal point.

Focal points are a key factor of landscape preference (Ulrich 1983) and are important for effective site layout as they influence the 'reading' of the scene. The focal point is used as a home-base from which the eye roams outward to read one part of the scene, comes back, and then roams again to read another part of the scene. It is therefore a reference point and a key ordering mechanism. In this respect the placement and number of focal points is critical. Points should be placed so that attention is 
drawn to the 'right' places - towards interesting parts of the site and away from places we do not want people to go. Within any one space there should only be one focal point, or if there are several then one must be dominant, as having too many makes the scene confusing as the eye does not know where to rest.

A series of strategically placed focal points (along with views and enclosure) are used to lead the viewer around the site in a planned manner. In other forms of design artwork is commonly used to create focal points - you are unlikely to have sculptural pieces around the farm but interesting gates, quaint sheds, old implements, single specimen trees, and highly contrasting trees among the general mass all lend themselves to use as focal points.

Enclosure, views and focal points interact to control the path of travel through a space, so that areas are revealed when you want them. This control of travel is the principle of circulation (Motloch 1991; Simonds 1983) where a deliberately organised progression around the site, through the series of spaces of different character, with strategically placed focal elements, makes that interesting 'journey' through the site. Circulation is triggered by the preference factors of focality (focal points), mystery (enclosure) and ground surface (ground plane) which are managed collectively to generate the required movement. On your farms the presence and location of traffic ways will be determined by your farming operations giving limited opportunity to manipulate those for visual effect, nevertheless focal points, views and enclosure could be managed around predetermined track locations to give added interest.

The layout and size of spaces, nature of enclosure, presence of focal points and views, and circulation is planned on a concept diagram. This is done before any detail of the design is developed. Using a site plan as a basis, we designate (i) size and location of spaces, (ii) the type of enclosure between spaces, (iii) the presence of views and where they will be seen from, including any enclosure manipulations to control viewing, (iv) locations of focal points, and (v) the desired circulation route. Some of these factors are already set by farming operations, but others could be manipulated. For example, views, spaces and enclosure can be managed by varying the amount of vegetation you use and the places you put it.

\section{Principles of plant composition}

As we determine site layout we designate certain areas to be planted, and the nature of that green mass must be considered carefully. Good plant composition can greatly enhance a site layout - poorly considered planting can detract from an otherwise good site layout. Planting design has two main components, one (usually smaller scale) involving composition of individual scenes, and another (usually larger scale) involving organisation of groups of plantings over the whole site that are seen sequentially as one moves through the site. 


\section{Individual compositions}

For individual (and usually smaller scale) compositions several principles apply. The most important of these is the interplay between repetition and variety. Repetition is established by associating plants of similar qualities, with obvious groupings between colour or form (Figure 8), or texture (Figure 9).

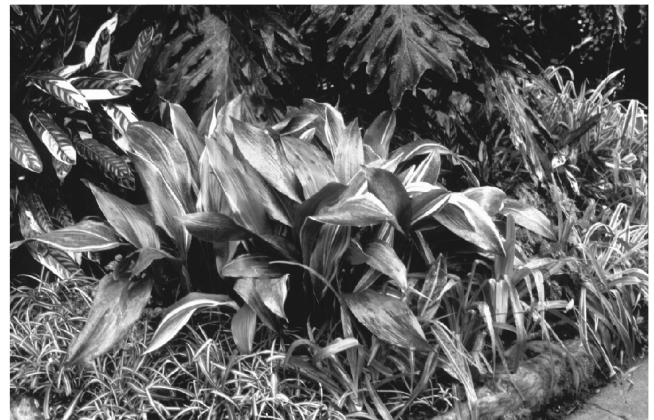

Figure 8. A combination of linear form.

Establishing repetitions within groups of plants requires you to observe the visual characters of plants - something to practice if you are not already familiar with each of line, form, colour and texture. Having recognised those characters, how do we combine them? For example, repeat just form, but more than one type, combining linear and round form (Figure 10).

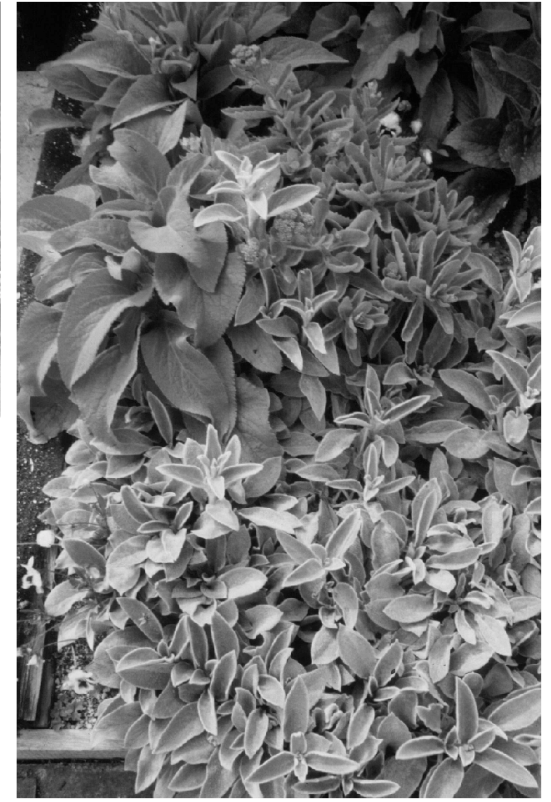

Figure 9. A texture combination.

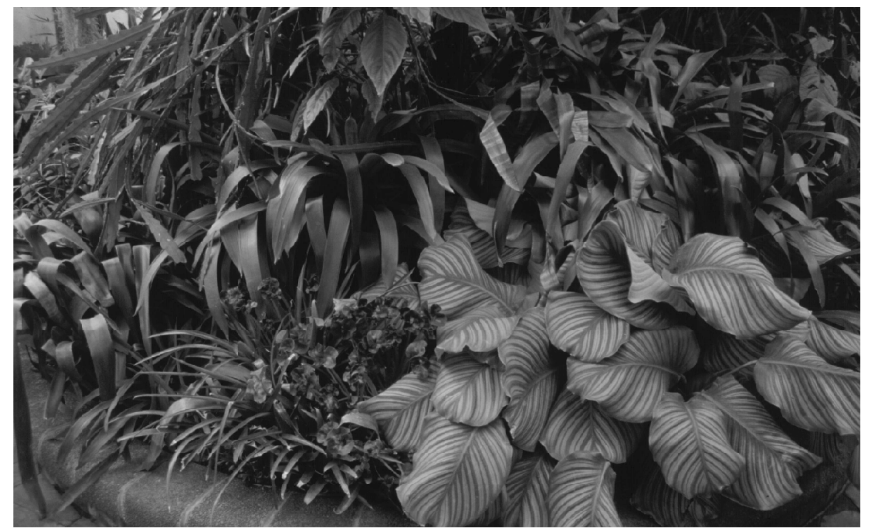

Figure 10. Linear and round form (texture and colour constant). 
Many of these apparently simple combinations, where one factor repeats and the others are held constant, are very appealing because they are at once interesting and easy to 'read'. More complex combinations repeat more than one factor at once - Figure 11 combines colour, form and texture. Note that although there seems to be many elements in Figure 11, they are also connected. Colour is held within a particular band, form is likewise limited, and within those limitations there are some differences in texture.

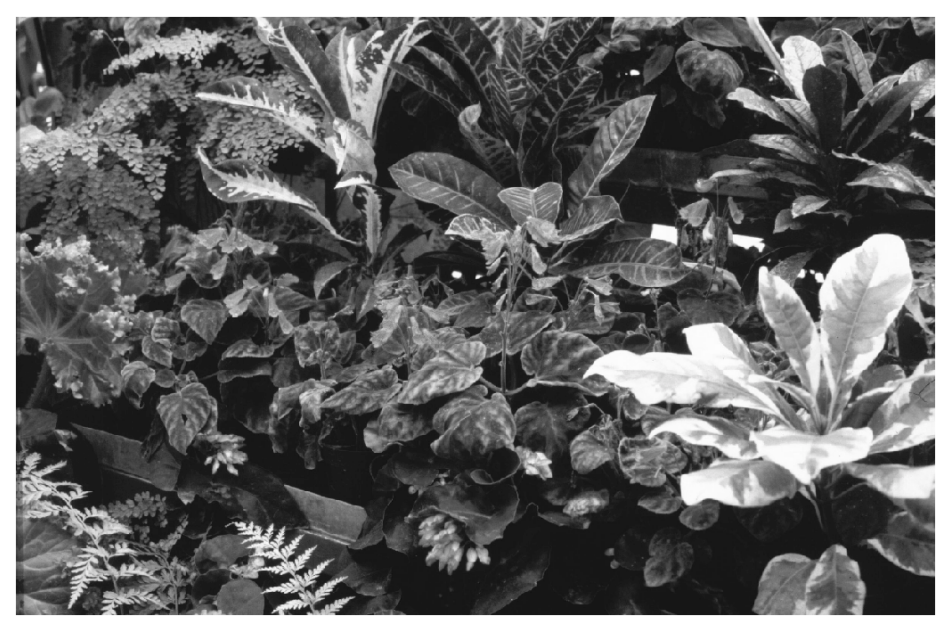

Figure 11. Colour, form and texture.

The skill with plant composition is knowing how much, of what, to put together. (The example that follows is taken from a small area of garden, imagine each plant as a tree in an area on your farm).

In Figure 12 the plants share the characters of grey colour and round form, but do not form a composition. In addition to the repeated character, the associated plants must be in proximity to one another and form a continuous grouping as the eye reads them together.

Figure 13 is better as there is one less plant species, and the remaining species are repeated. They are associated in groups rather than individually. Imagine this as a combination of Magnolia delavayi, blue atlas cedar, and flowering cherry.

At the same time though, too much repetition becomes boring (Figure 14). Consider your own plantings - what kind of repetition and variety have you used? 


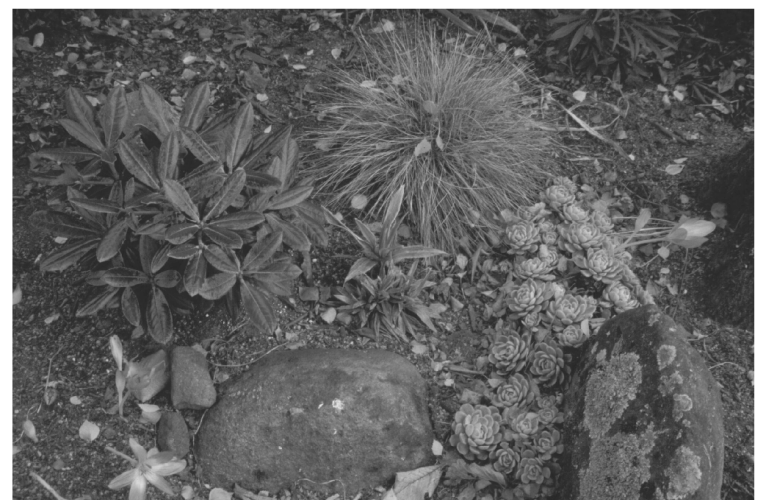

Figure 12. Poor composition.

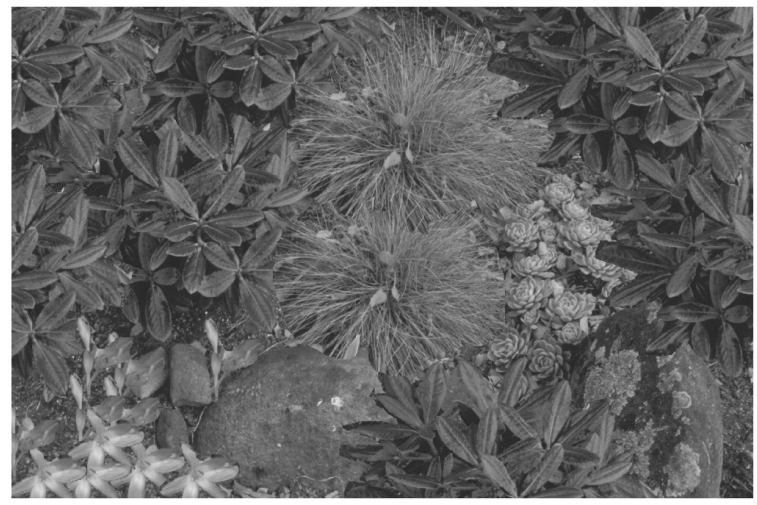

Figure 13. An improved composition.

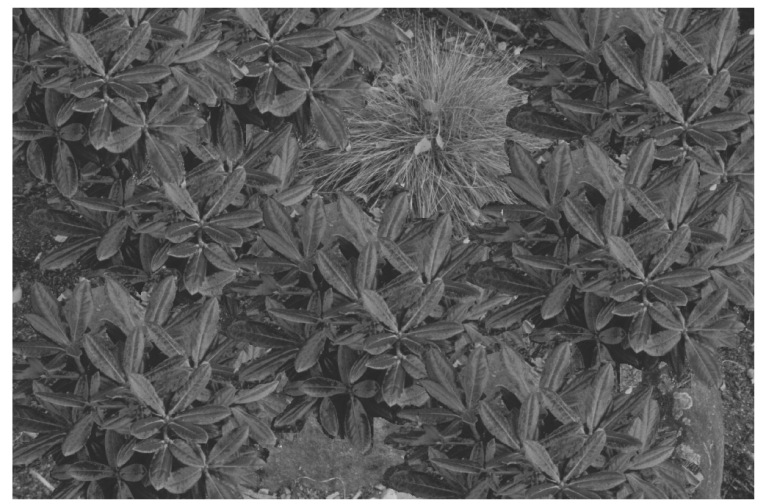

Figure 14. Too much repetition is boring. 
To avoid boredom we change some elements to give variety. But too much variation is confusing so we always try to strike a balance between repetition and variety. How many things should be grouped together? What is the effect of organisation within the group? What about shades and tones of colour? Indeed several factors influence the development of repetition and variety - landscape design is never boring as each set of factors influences the next! Consider some of these issues with the dot diagrams below (imagine each group as a group of trees, and each dot as a single tree). Combining too many different things is hard to read and confusing, but if all objects are the same then it is boring. Either combine a smaller number of objects, or organise many objects into a pattern.

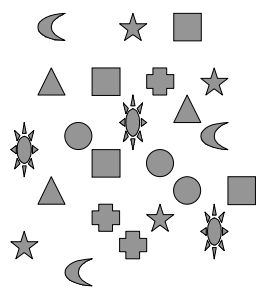

Too many objects, confusing.

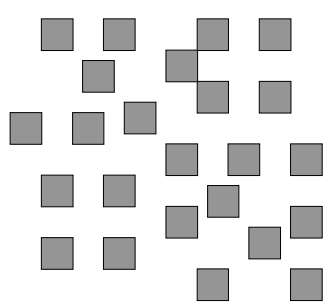

Too few objects, boring.

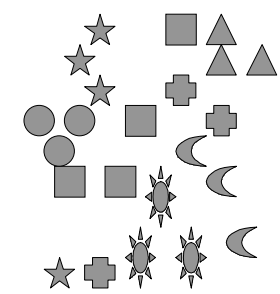

Organise many objects into groups.

Combinations are influenced by intensity. A small amount of intense colour has more influence than the same amount of a less intense colour.
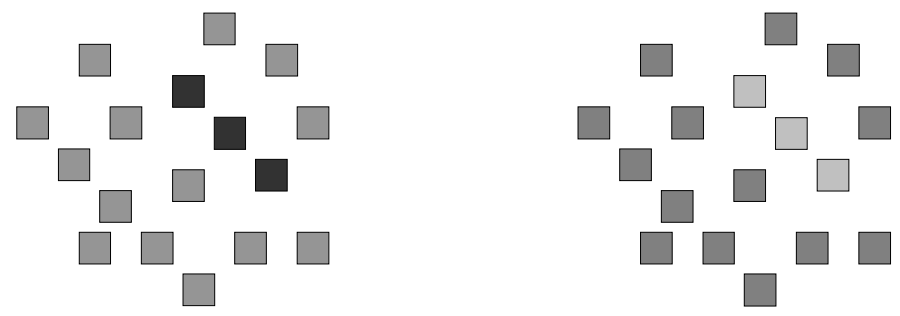

Combinations are also influenced by volume. A big group of one character will balance a scattered group of another character. (In this example intensities are about the same - altering the intensity of one will alter the effect).
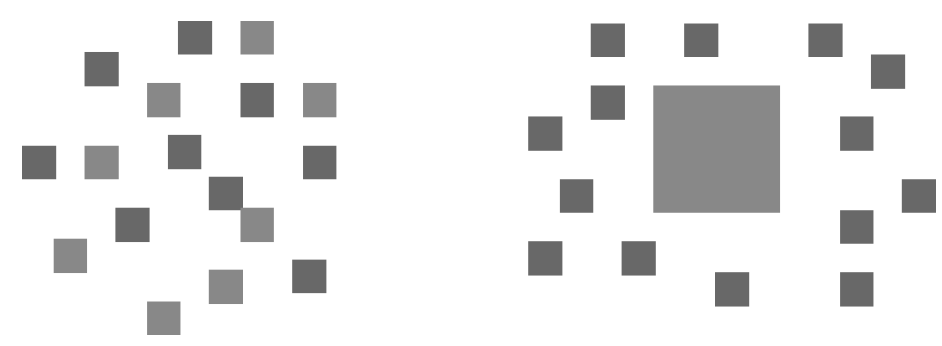
An important issue is the rate of change that occurs with the 'variety' element. Keeping one character the same but changing another (in Figure 13 colour and form stay the same but line and texture change) makes for gentle change. Conversely, strong contrast is formed through abrupt change, such as a sudden change of colour or form. Whether mild or strong contrast is required will depend on how much attention you wish to draw to that location. If you want to establish a focal point then strong contrast is usually needed. If you want a blended background change then more gentle change is usually needed.

Good compositions have the right amount of both repetition and variety. Repetition is established by (i) grouping trees with the same kind of colour, form or texture, or (ii) grouping different kinds of one factor (line, form, colour, texture) while limiting repetition in the other factors. Variety is established by (i) a small rate of change between factors in the composition, or (ii) abrupt change forming strong contrast. The more factors (line, form, colour, texture) that are included in the scene the more important it is to control the scene in terms of organisation and balance. Studied repetition and variety is the route to good planting, and given that there are so many possible combinations of characters the only real limits are your imaginations. In this overview it has not been possible to discuss details of matters such as colour effects and combinations, use of textures, interactions of factors and so on. Further reading on this topic can be found in various landscape references (Booth, 1983; Hannebaum, 1994; Lawson, 1996; Leszcynski, 1999).

\section{Organising planting over the whole site}

At a larger scale we also need to think about planting composition over the whole site. At this scale we are also looking for a studied series of repetition and variety, but how will this work over a larger area? The key issue is the use of themes, and the interface between them. One theme, say yellow-gold foliage, may be dominant in one part of the planting while elsewhere grey-maroon may be dominant (imagine this as a progression from one end of your farm to the other).

In the following example the two ends of the progression are quite different, there is no grey in the yellow end and there is no yellow in the grey end, nevertheless the series is connected through the sequential change between them. In the next example (Figure 15) the same kind of progression is illustrated with form. Again the two ends of the progression are quite different but the series is connected.
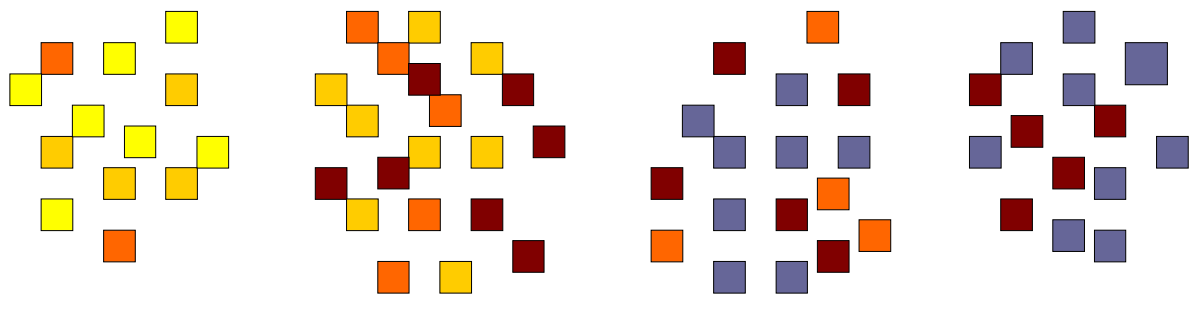

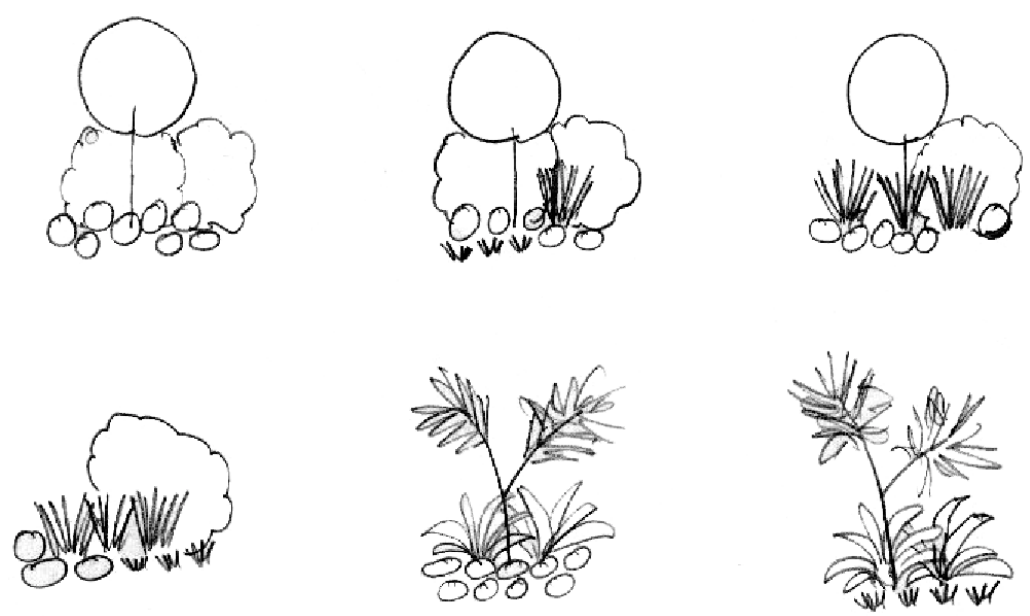

Figure 15. A sequential development of form.

Another way of developing a series over a large area is to repeat one character throughout, with other colours developed in different areas. For example the dot diagram below shows grey background with yellow foliage theme at one end, and grey background with purple foliage theme at the other end. There is a transition zone between. (The same interplay can be done with form and texture.)
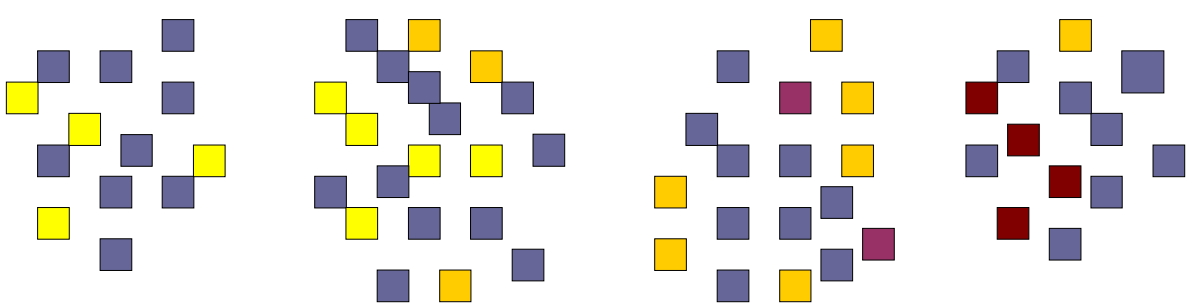

How do we plan planting over a whole site? Select the main themes for your planting (these themes are primarily visual but may also include categories of plants such as native plants.) Choose between the changing background and repeated background approach, then select the counterpoint themes. For example, you might select an evergreen foliage background of green and grey, with maroon foliage and pink flower variation. Counterpoint themes might be to increase grey in some areas, and to increase deciduous character in other areas. Place each theme in the chosen locations on the site. Blend the background in areas between. Do a layout sketch showing the planting layout.

A useful method for planning planting is the graphic concept where planting layout is shown graphically in terms of form, colour and texture. Actual species are not 
considered (you may well have some in mind, but this is not the focus of this plan). Figure 16 shows combinations of green and bronze foliage, and round and linear form. It clearly indicates what the planting pattern will look like, but is not committed to specific species and each symbol could be one of several species. For example, the green linear form could be a flax, or a cabbage tree. The graphic concept allows us to plan the layout and effect of planting without being fixed on any particular species.

Although there is plenty of literature describing the visual characters of plant and how to use them (Booth 1983; Hannebaum 1994; Leszczynski 1999), planting layout over whole sites is infrequently written about well in landscape literature. The graphic concept

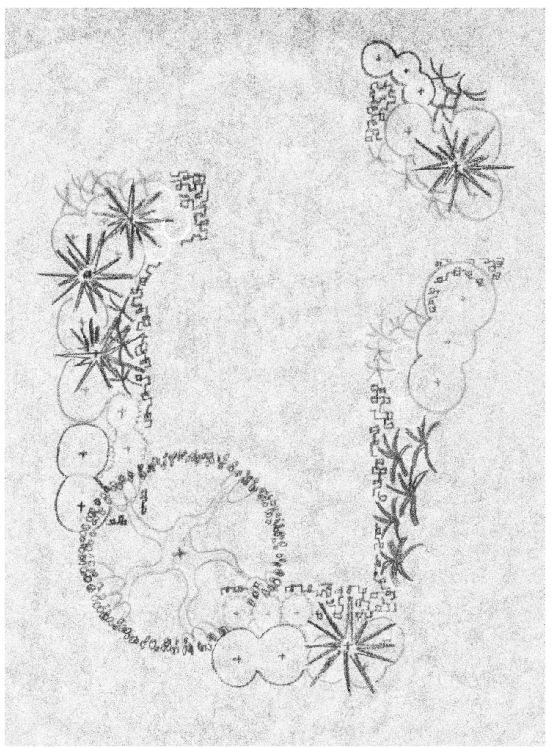

Figure 16. A graphic concept (drawing by T. Mullins 2002). (MacKay 2003) is a useful method for planting layout, but has not been fully described here.

\section{Exploring plant and design effects}

The discipline of site and planting layout provides structures and methods to organise the site, but at the same time plants are fun and exciting and there are many interesting types to try. Try Betula lutea (right) instead of just the standard Betula pendula. Experiment with less known or tried species - have you heard of Magnolia nitida and will it grow on your site? Have you considered some of the many and interesting Malus and Sorbus species which could readily be blended into your plantings? What about broad leaf evergreens like Eucryphia spp. or the big tree Photinia spp (not the shrub types) or Drimys, or some of the evergreen Quercus. Remember to think about the mix of deciduous and evergreen and seasonal

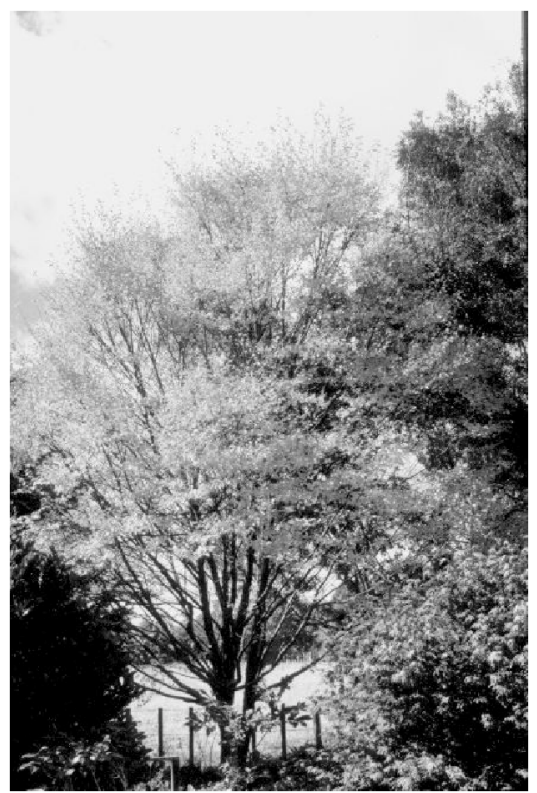


effect. Remember to utilise the features of flower and foliage in winter, and the colours of young foliage in spring. Make use of the colours of trunks and branches. Many species have superb qualities that make for exciting scenes - try and think past the species you already know.

\section{Conclusion}

Principles of landscape design are used to make farms aesthetically pleasing by manipulating spatial character, enclosure, views, and focal points. Planting design is used to organise combinations of colour, form and texture to create interesting scenes. The information presented here is a brief overview of some key principles; more information on landscape design can be found in the references listed below. In addition, the principles presented are from the point of view of a landscape designer and are likely to require adaptation for the farm situation to take account of the stock on any particular property.

Footnote: The conference presentation of this paper was accompanied by a series of images to illustrate the points being made. A colour printout of the presentation can be obtained (for a small cost) by contacting the author.

\section{References}

Booth, N.K. 1983. Basic elements of landscape architectural design. New York: Elsevier.

Farthing, D. and G. Farthing. 1991. Practical Garden Design. London: Foulsham and Co. Ltd.

Hannebaum, L.G. 1994. Landscape design: a practical approach. $3^{\text {rd }}$ ed. New Jersey: Prentice Hall.

Hobhouse, P. 1988. Garden Style. Leicester: Windward.

Lawson, A. 1996. A gardener's book of colour. New Zealand: Hodder and Stoughton. Leszczynski, N. A. 1999. Planting the landscape. New York: John Wiley and Sons.

MacKay, M.B. 2003. Study guide 3 for 171.360: planting design. Massey University.

Motloch, J.L. 1991. Introduction to Landscape Design. New York. Van Nostrand Reinhold.

Simonds, J.O. 1983. Landscape Architecture: the shaping of Man's natural environment. $2^{\text {nd }}$ edition. New York. Mc Graw Hill.

Ulrich, R.S. 1983. Aesthetic and affective responses to natural environment. pp. 85-125 in: I.Altman and J.F.Wohwill. (eds.). Behaviour and the natural environment. New York. Plenum Press. 